\title{
SURVEY TINGKAT KEBUGARAN JASMANI SISWA KELAS IV SDN PUHRUBUH I DAN MI MAMBAUL HIKAM DI KABUPATEN KEDIRI TAHUN AJARAN 2016/2017
}

\author{
Irma Wirnantika ${ }^{1}$, Budiman Agung Pratama ${ }^{2}$, Yulingga Nanda Hanief ${ }^{3}$ \\ ${ }^{1,2,3}$ Pendidikan Jasmani Kesehatan dan Rekreasi \\ Universitas Nusantara PGRI Kediri \\ E-mail: agung10@unpkediri.ac.id ${ }^{2}$,ynh90@unpkediri.ac.id ${ }^{3}$
}

Diterima: 17 November 2017; Lolos: 21 November 2017; Dipublikasikan: 21 November 2017

\begin{abstract}
Abstrak
Penelitian ini bertujuan untuk mengetahui kebugaran jasmani siswa kelas IV SDN Puhrubuh I dan MI Mambaul Hikam di Kabupaten Kediri tahun ajaran 2016/2017. Penelitian ini menggunakan pendekatan kuantitatif dengan teknik pendekatan survey tes. Populasi yang digunakan adalah siswa kelas IV putra putri dengan jumlah 24 siswa di SD Negeri Puhrubuh I dan MI Mambaul Hikam di Kecamatan Semen. Teknik sampling dalam penelitian ini menggunakan teknik sampel jenuh, dimana semua populasi dijadikan sebagai sampel. Instrumen penelitian dalam penelitian ini menggunakan tes dan pengukuran. Untuk mengetahui kebugaran jasmani pada siswa maka dilakukan Tes Kebugaran Jasmani Indonesia (TKJI). Berdasarkan analisis data, hasil tingkat kebugaran jasmani siswa SD Negeri Puhrubuh I dan MI Mambaul Hikam 11 siswa termasuk dalam kategori sedang dengan prosentase 45,83\%, 9 siswa termasuk dalam kategori kurang dengan prosentase $37,50 \%$, 2 siswa termasuk dalam kategori baik dengan prosentase $8,33 \%, 2$ siswa termasuk dalam kategori kurang sekali dengan prosentase $8,33 \%$. Berdasarkan hasil penelitian dan analisis deskriptif prosentase, maka dapat disimpulkan bahwa kebugaran jasmani siswa kelas IV SD Negeri Puhrubuh 1 dan MI Mambaul Hikam Kabupaten Kediri tahun ajaran 2016/2017 dalam kategori sedang dicapai sebanyak 11 siswa dengan jumlah prsentase $45,83 \%$.
\end{abstract}

Kata kunci: Survey, kebugaran jasmani, kebugaran.

\section{A SURVEY ON PHYSICAL FITNESS OF THE FOURTH GRADE STUDENTS OF SDN PUHRUBUH I AND MI MAMBAUL HIKAM IN KEDIRI REGENCY ACADEMIC YEAR 2016/2017}

\begin{abstract}
This study aims to determine the physical fitness of the fourth grade students of SDN Puhrubuh 1 and MI Mambaul Hikam in Kediri Regency academic year 2016/2017.This study uses quantitative approach with test survey technique. The population is 24 students infourth grade in SD Negeri Puhrubuh I and MI Mambaul Hikam in Semen Sub-district. Sampling technique in this research uses saturated sample technique, where all population used as sample. The research instrument in this research uses test and measurement. To know the physical fitness of the students the researchers performed the Tests of Physical Fitness Indonesia (TKJI). Data analysis, the results of the physical fitness level of
\end{abstract}

\begin{tabular}{cc}
\hline Email & agung10@unpkediri.ac.id ${ }^{2}$ \\
ynh90@unpkediri.ac.id & \\
No Handphone : 085784192666
\end{tabular}


elementary school students Puhrubuh 1 and MI Mambaul Hikam, there were 11 or $45,83 \%$ students who were included in the medium category, 9 or $37,50 \%$ students were included in the poor category, 2 or $8,33 \%$ students were included in both categories with percentage of, 2 or $8,33 \%$ students were included in the category of the least ones. According to the research results and percentage descriptive analysis, it can be concluded that physical fitness of fourth grade students of SDN Puhrubuh I and MI Mambaul Hikam 2016/2017 school year in the category medium reached as many as 11 or $45,83 \%$ students.

Keywords: Survey, physical fitness, fitness.

\section{PENDAHULUAN}

Saat ini pendidikan jasmani memegang peranan penting dalam mewujudkan tujuan pendidikan. According to the results of the Eurydice Report on physical education and sports in Europe (EACEA, 2013), all European countries recognize the importance of physical education at school. Menurut hasil Laporan Eurydice tentang pendidikan jasmani dan olahraga di Eropa (EACEA, 2013), semua negara Eropa menyadari pentingnya pendidikan jasmani di sekolah. Pendidikan jasmani merupakan bagian yang tidak dapat dipisahkan dari kehidupan manusia, melalui pendidikan jasmani manusia dapat belajar lebih banyak hal yang berhubungan dengan afektif, kongnitif, dan psikomotor yang merupakan bekal manusia untuk mencapai tujuan hidup (Hanief dan Sugito, 2015). Olahraga jasmani merupakan gerak psikomotorik manusia yang kompleks. Meningkatnya kesehatan badan identik dengan meningkatnya kebugaran jasmani, dimana dalam tubuh yang sehat tentu akan berpengaruh terhadap tercipta kesehatan jiwa, oleh karena itu agar menjadi insan yang utuh secara lahiriah maka kesehatan jasmani dan rohani harus di miliki oleh setiap individu, agar dapat hidup seimbang dan berjalan dengan tujuan hidup yang diharapkan.

Menurut Depdikbud, (1997:52), kebugaran jasmani adalah kemampuan tubuh seseorang untuk melaksanakan tugas dan pekerjaan sehari-hari dengan giat dan waspada tanpa mengalami kelelahan yang berarti, serta masih memiiki cadangaan energi untuk mengisi waktu luang dan menghadapi hal-hal darurat yang tidak terduga sebelumnya. Jadi, dapat diartikan kebugaran jasmani kemampuan seseorang untuk 
melakukan kegiatan sehari-hari dengan mudah tanpa merasa lelah dan masih mempunyai sisa atau cadangan tenaga untuk menikmati waktu senggang atau untuk keperluan yag sewaktu-waktu dapat digunakan, dengan demikian kebugaran jasmani merupakan wujud dari loyalitas fungsional seseorang untuk melakukan suatu pekerjaan secara tertentu dengan hasil yang baik atau memuaskan. Kebugaran jasmani dapat diperoleh melalui pendidikan jasmani dan kegiatan ekstrakulikuler. Kebugaran jasmani siswa yang baik akan menjamin kesiapan siswa dalam melaksanakkan tugas sehari - hari dan selalu menapakkan penampilan yang optimal. Agar kebugaran jasmani tetap terjaga, maka harus ditanamkan sejak dini mungkin dari pendidikan dasar, baik di rumah maupun di sekolah. Sebab perilaku kebugaran jasmani merupakan kondisi dan kebiasaan yang membutuhkan ketekunan dan usaha yang keras. Pendidikan jasmani yang diselenggarakan di sekolah dasar hendaknya dapat membentuk ketrampilan dasar bagi anak - anak Sekolah Dasar. Melalui berbagai bentuk ketrampilan gerak dasar akan dapat meningkatkan aktivitas dan pengembangan kemampuan anak.

Kebugaran jasmani bagi perkembangan anak usia sekolah dasar sangat dibutuhkan. Pada usia sekolah dasar adalah masa pertumbuhan dan perkembangan yang sangat cepat, baik jasmani maupun rohani. Anak usia sekolah dasar memiliki aktifitas yang tinggi dalam kehidupan sehari hari. Sehingga kebugaran jasmani bagi anak sekolah dasar adalah memberi manfaat bagi si anak untuk : 1) meningkatkan aktifitas bermain, 2) meningkatkan motivasi dalam diri anak (intrinsik), 3) meningkatkan semangat belajar dan berlatih, serta 4) meningkatkan kesehatan pribadi anak didik (Ibrahim, 2001:41).

Kebugaran jasmani akan mengantarkan anak didik menuju kesiapan jasmani, mental dan emosional, kematangan psikologis dan fisik, serta mengantarkan anak untuk semangat belajar dan berlatih sehingga akan tercapai prestasi belajar yang diharapkan. Tingkat kebugaran jasmani yang baik sebagai akibat latihan fisik yang teratur, dan dalam dosis rendah sampai sedang, akan berpengaruh terhadap fungsi - fungsi 
kognitif, seperti (1) kemampuan mengingat, (2) memecahkan masalah angka - angka, (3) kecermatan (Ibrahim, 2001:59).

Sekolah Dasar Negeri Puhrubuh I dan MI Mambaul Hikam terletak di desa Sidomulyo Kecamatan Semen Kabupaten Kediri. Sekolah Dasar Negeri Puhrubuh I terletak di zona suburban fringe, yaitu wilayah peralihan kota dan desa. Sedangkan MI Mambaul hikam wilayahnya terletak di pedesaan (rural). Oleh karena itu, hal tersebut merupakan suatu kondisi yang menarik untuk dikaji tentang tingkat kebugaran jasmani siswa Sekolah Dasar. Untuk mengetahui tingkat kesegaran jasmani siswa kelas SD Puhrubuh I dan MI Mambaul Hikam, perlu di adakan suatu penelitian secara obyektif. Obyek penelitian adalah seluruh siswa kelas IV di SD Negeri Puhrubuh I dan MI Mambaul Hikam di Kabupaten Kediri.

\section{METODE}

Penelitian ini menggunakan pendekatan metode penelitian deskriptif kuantitatif. Populasi dalam penelitian ini adalah siswa kelas IV SD Negeri Puhrubuh I dan MI Mambaul Hikam di Kabupaten Kediri yang terdiri dari 24 siswa. Teknik sampling yang digunakan adalahj sampel jenuh. Menurut Sugiyono (2001:16) sampling jenuh adalah teknik penentuan sampel bila semua anggota populasi digunakan sebagai sampel. Teknik pengumpulan data dengan menggunakan Tes Kesegaran Jasmani ndonesia (TKJI) tahun 20106 untuk usia 10 - 12 tahun (Mendiknas, 2010). Teknik yang dipakai dalam analisis data penelitian adalah menggunakan statistik diskriptif dengan metode diskriptif presentase, dengan pengelompokan kategori baik sekali, baik, sedang, kurang, dan kurang sekali. Adapun rumus untuk analisis deskriptif prosentase (DP) adalah:

$$
D P=\frac{n}{N} \times 100 \%
$$

Keterangan:

DP : skor yang diharapkan

$\mathrm{N} \quad$ : jumlah skor maksimum

n : jumlah skor yang diperoleh (Hanief dan Himawanto, 2017) 
Irma Wirnantika ${ }^{1}$, Budiman Agung Pratama ${ }^{2}$, Yulingga Nanda Hanief ${ }^{3}$

Survey Tingkat Kebugaran Jasmani Siswa Kelas 4 SDN Puhrubuh 1 dan Mi Mambaul Hikam di

Kabupaten Kediri Tahun Ajaran 2016/2017

\section{HASIL DAN PEMBAHASAN}

\section{Hasil}

1. Deskriptif Hasil Penilaian Kebugaran Jasmani Siswa Kelas IV SD Negeri Puhrubuh I Kecamatan Semen Kabupaten Kediri Tahun Pelajaran 2016/2017.

Dari hasil penelitian menunjukkan bahwa pada masing-masing kelompok dan jenis kelamin, pada berbagai tingkatan sesuai norma tes kebugaran jasmani Indonesia tahun 2010 diperoleh data sebagai berikut :

a. Siswa Putra kelas IV SD negeri Puhrubuh I Kecamatan Semen Kabupaten Kediri tahun pelajaran 2016/2017 untuk masing-masing tes kebugaran jasmani menunjukkan skor tertinggi adalah pada butir baring duduk dengan skor 23 kali atau nilai 5 sedangkan untuk skor terendah adalah lari $600 \mathrm{~m}$ dengan skor 4'32" atau nilai 1.

b. Siswa Putri kelas IV SD Negeri Puhrubuh I Kecamatan Semen Kabupaten Kediri tahun pelajaran 2016/2017 untuk masing-masing tes kebugaran jasmani menunjukkan skor tertinggi adalah pada butir tes lari $40 \mathrm{~m}$ dengan skor 6,6" atau nilai 5, gantung siku tekuk dengan skor 57" atau nilai 5 dan baring duduk dengan skor 27 kali atau nilai 5 sedangkan untuk skor terendah adalah lari $600 \mathrm{~m}$ dengan skor 4'56" atau nilai 1.

Tabel 1 Deskripsi Skor Tertinggi, Skor Terendah, dan Rata - rata Tes Kebugaran Jasmani Siswa SD Negeri Puhrubuh I Kecamatan Semen Kabupaten Kediri Tahun Pelajaran 2016/2017

\begin{tabular}{clccc}
\hline No & \multicolumn{1}{c}{ Jenis Tes } & $\begin{array}{c}\text { Skor } \\
\text { Tertingi }\end{array}$ & $\begin{array}{c}\text { Skor } \\
\text { Terendah }\end{array}$ & Rata - rata \\
\hline 1 & Lari $40 \mathrm{~m}$ & $6,6^{\prime \prime}$ & $10,0^{\prime \prime}$ & $7,81^{\prime \prime}$ \\
\hline 2 & Gantung siku tekuk & $57^{\prime \prime}$ & $3^{\prime \prime}$ & $14,25^{\prime \prime}$ \\
\hline 3 & $\begin{array}{l}\text { Baring duduk } 30 \\
\text { detik }\end{array}$ & 27 kali & 13 kali & 19 kali \\
\hline 4 & Loncat tegak & $35 \mathrm{~cm}$ & $20 \mathrm{~cm}$ & $29 \mathrm{~cm}$ \\
\hline 5 & Lari $600 \mathrm{~m}$ & $2^{\prime} 50^{\prime \prime}$ & $4^{\prime} 56^{\prime \prime}$ & $3^{\prime} 52^{\prime \prime}$ \\
\hline
\end{tabular}

(Sumber: Data Penelitian) 
2. Deskriptif Hasil Penilaian Kebugaran Jasmani Siswa Kelas IV MI Mambaul Hikam Kecamatan Semen Kabupaten Kediri Tahun Pelajaran 2016/2017

a. Siswa Putra kelas IV MI Mambaul Hikam Kecamatan Semen Kabupaten Kediri tahun pelajaran 2016/2017 untuk masing masing tes kebugaran jasmani menunjukkan skor tertinggi adalah pada butir gantung siku tekuk dengan skor 60" atau nilai 5 sedangkan skor terendah adalah pada butir lari $600 \mathrm{~m}$ dengan skor 8'58" atau nilai 1.

b. Siswa Putri kelas IV MI Mambaul Hikam Kecamatan Semen Kabupaten Kediri tahun pelajaran 2016/2017 untuk masing-masing tes kebugaran jasmani menunjukkan skor tertinggi adalah pada butir baring duduk dengan skor 28 kali atau nilai 5 dan gantung siku tekuk dengan skor 57" atau nilai 5 sedangkan skor terendah adalah pada butir lari 600 m dengan skor 8'58" atau nilai 1.

Tabel 2 Deskripsi Skor Tertinggi, Skor Terendah, dan Rata - rata Tes Kebugaran Jasmani Siswa MI Mambaul Hikam Kecamatan Semen Kabupaten Kediri Tahun Pelajaran 2016/2017

\begin{tabular}{clccc}
\hline No & \multicolumn{1}{c}{ Jenis Tes } & $\begin{array}{c}\text { Skor } \\
\text { Tertingi }\end{array}$ & $\begin{array}{c}\text { Skor } \\
\text { Terendah }\end{array}$ & Rata - rata \\
\hline 1 & Lari $40 \mathrm{~m}$ & $6,94^{\prime \prime}$ & $9,2^{\prime \prime}$ & $7,63^{\prime \prime}$ \\
\hline 2 & Gantung siku tekuk & $60^{\prime \prime}$ & $3^{\prime \prime}$ & $24 "$ \\
\hline 3 & $\begin{array}{l}\text { Baring duduk } 30 \\
\text { detik }\end{array}$ & $28 \mathrm{kali}$ & $10 \mathrm{kali}$ & $18 \mathrm{kali}$ \\
\hline 4 & Loncat tegak & $36 \mathrm{~cm}$ & $15 \mathrm{~cm}$ & $28 \mathrm{~cm}$ \\
\hline 5 & Lari $600 \mathrm{~m}$ & $2^{\prime} 49^{\prime \prime}$ & $8^{\prime} 58^{\prime \prime}$ & 4,18 \\
\hline
\end{tabular}

(Sumber: Data Penelitian)

3. Analisis Diskriptif Prosentase Tes Kebugaran Jasmani Kelas IV SD Negeri Puhrubuh 1 dan MI Mambaul Hikam Kecamatan Semen Kabupaten Kediri Tahun Pelajaran 2016/2017.

Dengan menggunakan analisis deskriptif prosentase diperoleh klasifikasi data atau kategori tingkat kebugaran jasmani pada siswa kelas IV atas SD Negeri Puhrubuh I Kecamatan Semen Kabupaten Kediri Tahun Pelajaran 2016/2017 sebagai berikut : 
a. Untuk siswa kelas IV SD Negeri Puhrubuh I Kecamatan Semen Kabupaten Kediri Tahun Pelajaran 2016/2017: kategori baik sekali sebanyak 0 siswa atau tidak ada, dan dengan jumlah persentase $0 \%$. Kategori baik sebanyak 1 siswa dengan persentase $8,33 \%$. Kategori Sedang sebanyak 5 siswa dengan jumlah persentase $41,67 \%$. Kategori Kurang sebanyak 5 siswa dengan jumlah persentase $41,67 \%$. Kategori Kurang Sekali sebanyak 1 siswa dengan persentase $8,33 \%$.

b. Untuk siswa kelas IV MI Mambaul Hikam Kecamatan Semen Kabupaten Kediri Tahun Pelajran 2016/2017: kategori baik sekali sebayak 0 siswa atau tidak ada, dengan persentase $0 \%$. Kategori baik sebanyak 1 siswa dengan persentase $8,33 \%$. Kategori sedang sebanyak 6 siswa dengan persentase $50,00 \%$. Kategori kurang sebanyak 4 siswa dengan persentase $33,33 \%$. Kategori kurang sekali sebanyak 1 siswa dengan persentase $8,33 \%$.

Tabel 3 Deskripsi Tingkat Kebugaran Jasmani Siswa Kelas IV SD Negeri Puhrubuh I dan MI Mambaul Hikam Kecamatan Semen Kabupaten Kediri Tahun Pelajaran 2016/2017

\begin{tabular}{cclcc}
\hline No & Jumlah Nilai & \multicolumn{1}{c}{ Klasifikasi } & Frekuensi & $\begin{array}{c}\text { Persentase } \\
(\%)\end{array}$ \\
\hline 1 & $22-25$ & Baik Sekali (BS) & 0 & $0 \%$ \\
\hline 2 & $18-21$ & Baik (B) & 2 & $8,33 \%$ \\
\hline 3 & $14-17$ & Sedang (S) & 11 & $45,83 \%$ \\
\hline 4 & $10-13$ & Kurang (K) & 9 & $37,50 \%$ \\
\hline 5 & $05-09$ & Kurang Sekali (KS) & 2 & $8,33 \%$ \\
\hline & & & $\Sigma \mathrm{f}=24$ & $100 \%$ \\
\hline
\end{tabular}

(Sumber: Data Penelitian)

Tabel 3 menunjukkan rekapitulasi hasi penelitian keseluruhan tentang gambaran tingkat kebugaran jasmani seluruh siswa kelas IV SD Negeri Puhrubuh I dan MI Mambaul Hikam Kecamatan Semen Kabupaten Kediri Tahun Pelajaran 2016/2017 sebagai berikut :

a. Kategori baik sekali sebanyak 0 siswa, jumlah prosentase $0 \%$.

b. Kategori baik sebanyak 2 siswa, jumlah prosentase $8,33 \%$.

c. Kategori sedang sebanyak 11 siswa, jumlah prosentase $45,83 \%$. 
d. Kategori kurang sebanyak 9 siswa, jumlah prosentase 37,50\%.

e. Kategori kurang sekali sebanyak 2 siswa, 8,33\%.

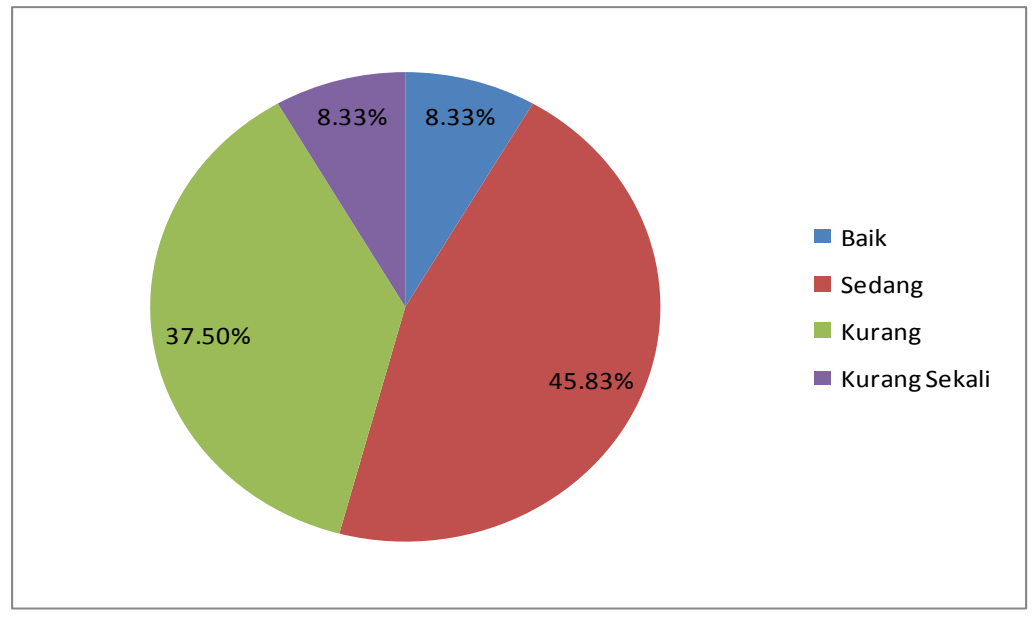

Gambar 1 Diagram Prosentase Tigkat Kebugaran Jasmani Siswa Kelas IV SD Negeri Puhrubuh I dan MI Mambaul Hikam Kecamatan Semen Kabupaten Kediri Tahun Pelajaran 2016/2017.

(Sumber: Data Penelitian)

\section{Pembahasan}

Pencapaian hasil tingkat kebugaran jasmani pada siswa kelas IV SD Negeri Puhrubuh 1 dan MI Mambaul Hikam Kecamatan Semen Kabupaten Kediri tahun pelajaran 2016/2017 masih dipengaruhi oleh beberapa faktor. Berdasarkan pendapat Dangsina Moeloek dalam bukunya "Kesehatan Olahraga" yang memperngaruhi tingkat kesegaran jasmani seseorang ada 5 faktor, yaitu:

a. Faktor makanan dan gizi

b. Faktor tidur dan istirahat

c. Faktor kebiasaan hidup sehat

d. Faktor latihan dan olahraga

e. Faktor lingkungan

Berdasarkan pendapat tesebut, maka pencapaian hasil tingkat kesegaran jasmani pada siswa kelas atas Sekolah Dasar Negeri Puhrubuh I dan MI Mambaul Hikam Kecamatan Semen Kabupaten Kediri tahun pelajaran 2016/2017 adalah sebagai berikut: 
a. Untuk kategori Baik Sekali (BS), tak satupun siswa mencapai kategori baik sekali. Hal ini dikarenakan tak seorang siswa pun yang terbina dalam kegiatan/aktifitas olahraga secara khusus, seperti masuk klub olahraga.

b. Untuk kategori Baik (B), dicapai sebanyak 2 siswa. Dalam kenyataannya, para siswa setelah jam sekolah setiap sore melakukan aktivitas olahraga seperti bersepeda dan mengikuti ekstra kulikuler olahraga di sekolah.

c. Untuk kategori Sedang (S), dicapai sebanyak 11 siswa. Hal ini dikarenakan di luar jam sekolah mereka hanya mengikuti ekstrakulikuler olahraga di sekolah saja, selebihnya mengikuti kegiatan les atau hanya bermain-main pada sore hari disekitar tempat tinggalnya.

d. Untuk kategori Kurang (K), dicapai sebanyak 9 siswa. Mereka yang termasuk dalam kategori kurang ini hanya beberapa anak saja yang mengikuti kegiatan ekstrakulikuler olahraga di sekolah, diantara mereka banyak yang mengikuti kegiatan les atau Sekolah Taman Pendidikan Qur'an (TPQ) pada sore hari, mereka banyak duduk dari pada aktifitas geraknya.

e. Untuk kategori Kurang Sekali (KS), dicapai sebanyak 2 siswa. Hal ini dikarenakan kondisi badan siswa sebagian ada yang kegemukan sehingga mempengaruhi kelincahan dan kecepatan gerak. Aktifitas fisik dan olahraga mereka di luar jam sekolah juga kurang.

\section{KESIMPULAN DAN SARAN}

\section{Kesimpulan}

Berdasarkan hasil penelitian dan analisis deskriptif presentase, maka dapat dsimpulkan bahwa kebugaran jasmani siswa kelas IV Sekolah Dasar Puhrubuh I dan MI Mambaul Hikam Kecamatan Semen Kabupaten Kediri Tahun Pelajaran 2016/2017 dalam kategori sedang. 


\section{Saran}

1. Untuk mengetahui tingkat kebugaran jasmani pada anak-anak usia Sekolah Dasar, seorang guru penjasorkes dapat menggunakan pedoman dan pengukuran Tes Kebugaran Jasmani Indonesia (TKJI) yang diterbitkan oleh Mendiknas tahun 2010 sesuai dengan kelompok usia.

2. Dengan tingkat kebugaran jasmani pada kategori sedang, guru sebaiknya meningkatkan kebugaran jasmani para siswa, dapat berupa latihan maupun permainan yang arahnya untuk meningkatkan kebugaran jasmani.

3. Dalam melakukan latihan guna meningkatkan kebugaran jasmani peserta didik, seorang guru / pembina harus memperhatikan prinsip-prinsip latihan, agar tujuan latihan dapat tercapai.

4. Aktivitas seperti olahraga dan juga kegiatan - kegiatan yang dapat meningkatkan kebugaran jasmani perlu diupayakan bagi siswa, sehingga dimungkinkan dapat menambah kesiapan siswa dalam belajar demi meningkatkan prestasi.

5. Diharapkan peran aktif pemerintah, guru, pembina, pelatih ataupun semua yang berkecimpung di dalam dunia pendidikan berupaya meningkatkan kebugaran jasmani siswa usia Sekolah Dasar, serta dapat memberikan pembinaan yang tepat bagi anak usia Sekolah Dasar di masing - masing sekolah.

\section{DAFTAR PUSTAKA}

Dekdikbud, 1997. Petunjuk Pelaksanaan Pola Umum dan Pengembangan Kesegaran Jasmani : Pusegjas Jakarta.

European Commission/EACEA/Eurydice (2013). Physical Education and Sportat School in Europe. Eurydice Report. Luxembourg: Publications Office of the European Union.

Hanief, Yulingga Nanda and Sugito. "Membentuk Gerak Dasar Pada Siswa Sekolah Dasar Melalui Permainan Tradisional." Jurnal SPORTIF 1.1 (2015): 60-73.

Hanief, Yulingga Nanda dan Himawanto, Wasis. 2017. Statistik Pendidikan. Yogyakarta: Penerbit Deepublish. 
Ibrahim Rusli, 2001. Landasan Psikologis Pendidikan Jasmai di Sekolah Dasar, Jakarta : Depdiknas.

Mendiknas, 2010. Tes Kesegaran Jasmani Indonesia untuk anak umur 10 - 12 tahun, Jakarta : Pusat Kesegaran Jasmani dan Rekreasi

Sugiyono. 2001. Metode Penelitian Bisnis. Bandung: CV Alfabeta.

Vamos, Ảgnes dan Tamas Doczi. "Everyday Physical Education: Functional and Dysfunctional Consequences in Hungarian Public Education" Physical Culture and Sport. Studies and Research, 67.1 (2015): 20-30. Retrieved 16 November 2017, from doi:10.1515/pcssr-2015-0020. 